\title{
Streptococcal toxic-shock syndrome
}

INSERM

\section{Source}

INSERM. (1999). Orphanet: an online rare disease and orphan drug data base.

Streptococcal toxic-shock syndrome. ORPHA:99918

Streptococcal toxic-shock syndrome (streptococcal TSS) is an acute disease mediated by the production of superantigenic toxins characterized by the sudden onset of fever and other febrile symptoms, pain, multisystem organ involvement and potentially leading to coma, shock and death due to a Streptococcus pyogenes infection. 